\title{
THE STUDY OF THE “CETUS” UNMANNED AERIAL VEHICLE FOR TOPOGRAPHIC AERIAL SURVEYING
}

\author{
Volodymyr HLOTOV (D) ${ }^{1}$, Alla HUNINA ${ }^{\circledR 1}{ }^{1}$, Ihor KOLB ${ }^{\circledR 1}$, \\ Vadim KOLESNICHENKO (D2) Ihor TREVOHO (1) ${ }^{*}$ \\ ${ }^{1}$ Lviv Polytechnic National University, Lviv, Ukraine \\ ${ }^{2}$ Abris Design Group, Kyiv, Ukraine
}

Received 17 February 2020; accepted 14 June 2021

\begin{abstract}
The work aims to analyze and study the possibilities of using "Cetus" unmanned aerial vehicle (UAV) for performing topographic aerial surveys. The authors developed and tested aircraft-type UAV for topographic aerial photography. The studies were conducted on a specialized landfill, at which there is an appropriate number of situational points whose coordinates are determined with high accuracy. These points were used as both reference and control points. The obtained UAV aerial survey materials were subjected to a phototriangulation process to determine the orientation elements and to analyze, first and foremost, the angular orientation elements. The surveying was carried out on a mountainous territory, where the spatial coordinates of 37 situational points were determined by the method of ground-based GPS survey with an average accuracy of up to $0.05 \mathrm{~m}$. These points were used as reference and control points. Aerial photography was performed in such a way that the scale of the images was as uniform as possible.

The design solutions implemented in the Cetus UAV provide all the possibilities to perform aerial surveys of territories in strict compliance with the projected flight parameters. UAV equipment provides the necessary real-time correction of the position of the aerial camera. At the same time the optimum straightness of routes, stability of scales and mutual overlapping of pictures is reached. Regarding the accuracy of obtaining the spatial coordinates of the points of terrain objects, using "Cetus" UAV surveys, plans can even be made on a scale of even 1: 1000. As a result of the creation of the UAV "Cetus", it became possible to perform the topographic aerial survey of the territories and to create large-scale orthophotos that fully meet the instructions. As a result of testing the "Cetus" UAV, it can be used in production processes when drawing up topographic plans for a large-scale series: 1: 1000 - 1: 5000, which will significantly save the cost of performing topographic work.
\end{abstract}

Keywords: unmanned aerial vehicle, roll, pitch, drift angle, phototriangulation, accuracy assessment.

\section{Introduction}

The content of this study was to determine the suitability of the "Cetus" unmanned aerial vehicle (UAV) for using the aero materials obtained to create largescale topographic plans and special plans for their use in various branches of science and technology. The hypothesis is the possibility of creating such a UAV that would most accurately reproduce the work during aerial photography of a manned aircraft. The essence of the main idea is to design and implement these requirements into reality. The novelty is that this type of UAV can be made since studies on its suitability for topographic aerial surveying have confirmed this idea (Hlotov et al., 2014, 2018).
An analysis of the recent studies results suggests that the use of UAVs has excellent prospects when shooting objects of small area and when shooting linear objects (Haletsky et al., 2012a, 2012b; Hlotov et al., 2018). The use of UAVs allowing easily capture hard-to-reach areas, and obtain high accuracy in determining the spatial coordinates of object points. In other words, modern technologies for orthophoto and topographic plans are based on the use of UAV digital aerial materials. To confirm this conclusion, we will analyze the recent studies, possibilities, and prospects of using UAVs for topographic aerial surveying. The possibility of using UAV as a new means of obtaining photogrammetric information comes from the disadvantages of two traditional methods of obtaining data with the help of space satellites and human-crewed aerial

*Corresponding author. E-mail: itrevoho@gmail.com

Copyright @ 2021 The Author(s). Published by Vilnius Gediminas Technical University

This is an Open Access article distributed under the terms of the Creative Commons Attribution License (http://creativecommons.org/licenses/by/4.0/), which permits unrestricted use, distribution, and reproduction in any medium, provided the original author and source are credited. 
vehicles, namely, the ability to shoot from low altitudes and directly in the area of objects, obtain high-resolution images, use in zones of emergencies without risk to the life and health of pilots, profitability (Hlotov et al., 2018).

It should be noted that the technology of aerial surveying from UAVs has been primarily developed to date. However, there are still enough problems that need to be addressed (Haletsky et al., 2012a, 2012b; Hlotov et al., 2014, 2018).

One of the problems of using UAVs for high-precision mapping is the inability to install an accurate stabilization system on these devices and determine the angular elements of the external image orientation (INS). At the same time, the question of determining linear elements has been resolved since two frequency GPS receivers have been used on UAVs for several years. The accuracy of determining the projection center coordinates of these receivers reaches already more than a few centimeters. On the other hand, precision camera calibration is performed, which ensures the corresponding accuracy of determining the elements of interior orientation (Hlotov \& Hunina, 2017; Hlotov et al., 2018). So, summing up the above, it is necessary to focus on the fact that there is an urgent problem of studying the actual angular values of exterior orientation elements and then of a priori estimation of the accuracy of these elements.

This statement of the problem differs from the classical methodology. In determining the geodetic coordinates of the points of a terrain object, the question of their definition is emphasized, which is solved using an iterative process (Hlotov \& Hunina, 2018). Coordinate values are found with the accuracy of calculations, which cannot guarantee the necessary accuracy in determining the above coordinates. After all, this accuracy is determined by the measurement accuracy, which is not involved in the calculations. Then these errors can be introduced into the numerical values of the corresponding observations, and new coordinates can be obtained. Based on this, in the future, we can conclude about the possible accuracy of the calculations. However, such an approach is purely practical and does not make it possible to establish an a priori estimate of accuracy. Therefore, below is proposed a method developed by the authors to solve such a problem.

\section{Previous research}

The article (Levytskyi, 2008) examined the development of remote sensing technologies based on UAVs. A brief overview of UAVs, the technology of creating a digital terrain model (DTM) based on digital aerial survey materials, as well as the prospects of using a DTM for solving surveying tasks are given. The accuracy of the obtained DTM was assessed by comparing two DTMs - obtained from aerial survey materials during processing in Photo Scan Pro software and constructed from ground-based total station survey data. The analysis of the accuracy assessment showed that the differences in the coordinates in the overlapping zones when building the model in different areas of the survey ranged from 0.02 to $0.08 \mathrm{~m}$ with an aerial survey height of $150-250 \mathrm{~m}$, which corresponds to approximately $0.5-1.5$-pixel sizes in meters. A significant difference in the heights of the route is due to the significant difference in heights in the section (up to $80 \mathrm{~m}$ ). The authors did not mention the planning of the aerial survey project and its implementation, which is a no less important step in obtaining UAV data. Experience has shown that careful development of aircraft routes and flexible real-time project management of aerial survey operations play an essential role in achieving productive results and safe shooting.

Rokhmana (2015) and Bryson et al. (2010) provide practical research on the use of UAVs for mapping purposes. The system consists of UAVs, nonmetric digital survey camera (DSC), digital photogrammetric data processing: algorithm structure, and free open access GIS for visualization. This system can shoot with a spatial resolution of $10 \mathrm{~cm}$ and measure the area of the plot. The main outputs of the system are orthophotos and DTMs.

Part of the data obtained from the orthophoto plan is used for establishing cadastral boundaries and monitoring of vegetation. The orthophoto plan provides visual decoding of the structure of individual trees, plant density, and area, while DTM provides information about tree height and topography of the terrain with an accuracy of 3-6 pixels or $0.5-2.5 \mathrm{~m}$, the accuracy of the planned coordinates reaches from $10-40 \mathrm{~cm}$. However, the work did not consider how it would be possible to improve the process of creating orthophoto maps in order to improve accuracy.

Tsytsokhov and Boiko (2014) discusses such UAV models as Trimble UX5 and Zala 421-16EM. To obtain orthophoto maps of various scales (1:2000, 1: 1000 and 1: 500 ), such UAVs will be an ideal tool, both in the field and in urban areas. The processing of images obtained from a UAV consists of three main stages:

- pre-processing - the raw images are synchronized with the accumulated data of GPS observations and correct their distortions;

- registration - generation of point functions and their group equalization;

- DTM generation - 3D point generation, point classification.

Although the authors say that the use of Trimble UX5 and Zala 421-16EM UAVs for aerial surveying allowing obtain high-quality orthophoto maps, however, in the conclusions, there is no comparative analysis of the coordinates measured on the orthophoto map with the coordinates measured on the ground.

Shevenia (2013) presents the technology of creation of digital topographic plans of scale 1: 2000, which consists of the following stages: preparatory works; aerial surveying with the use of UAVs; photogrammetric thickening of the support grid; creation of a matrix of heights; creation of orthophoto plan; camera decryption, object vectorization; field decryption, coordination of buildings and structures; creation of digital topographic plans. In our opinion, this article does not analyze the factors that may affect the quality of the data obtained. 
Kostyuk (2011) discusses the peculiarities of the choice of digital cameras and the calculation of aerial surveying parameters performed from ultra-light UAVs. The method of operative assessment of the quality of the aerial survey with UAV is presented. The authors highlight a number of problems associated with aerial work for mapping purposes: the choice of aerial equipment, designing aerial surveying and prompt assessment of the quality of the materials received. The most critical features of cameras are the presence of manual focus, the physical size of the matrix, the resolution of pictures, the angle of coverage, and the weight of the camera. To assess the quality of the materials received, the software was developed and implemented in the form of GIS Mapinfo. The program, according to the data obtained from the UAV at the time of the shooting, builds a conditional picture frame, which assesses the coverage of a given area by aerial surveying. The developed method of estimation of the quality of aerial surveys in real-time allows avoiding repeated departures on the taken sites. The authors argue that this solution, in conjunction with the choice of camera, allows the use of ultra-light UAVs as full-function aerial filming complexes, but the results of the evaluation of the accuracy of the created materials are not given.

Fernández-Hernandez et al. (2015) presents the photogrammetric module to create a high-resolution $3 \mathrm{D}$ model. The equipment was chosen to create an orthophoto map and a DTM of the Celtic settlement in Cogotas (Spain). The instrumentation was a Microdrone md4-1000, with an Olympus EPL-2 digital camera and a Leica 1200 Global global positioning system that works in real-time kinematic (RTK). The selected UAV contains four rotating wings that allow steady flight at low altitudes. The UAV also contains navigation sensors (gyroscope, accelerometer, magnetometer and barometer) and secondary sensors (hygrometer and thermometer). The flight was carried out from a height of $65 \mathrm{~m}$, on an area of 5 ha. The route covered a total of 30 images in three routes, a longitudinal overlap of $80 \%$ and a transverse overlap of $40 \%$. The workflow included the following steps: designing routes, aerial surveying, image processing, generalizing the density surface, creating an orthophoto map and evaluating accuracy. The accuracy of the planned coordinates of the created model was $5 \mathrm{~cm}$, accuracy in height $-6 \mathrm{~cm}$. The results of the photogrammetric analysis of archaeological excavations obtained from the UAV showed that the approach proposed by the authors is semi-automatic, inexpensive, effective, and high-quality. However, in our opinion, the work does not consider the solution to the problem of automatic identification of control points.

For more than ten years, domestic specialists have been engaged in the development and research of aerial UAVs (Haletsky, 2012a, 2012b; Hlotov et al., 2014). The study was started by testing the "Bird" UAV, with a two-cylinder internal combustion engine. When analyzing the results, significant shortcomings of the proposed
UAV design and aerial survey technology were identified, in particular: insufficiently accurate observance of flight speed and altitude, different scale of the images, poor overlap and straightness of the routes, drift and tilt angles of the images exceeded tolerances, insufficient protection of the digital camera, inconvenient access to the camera, high level of vibration. Based on the results of processing the obtained materials, it is concluded that it is necessary to improve the design and technological scheme of the UAV. For this purpose, a specialized small "Pegasus" UAV with an electric motor was developed. Particular attention in the design of the aircraft was focused on protecting onboard equipment and a digital camera during cabling and glide path. The aircraft was equipped with a new longrange remote-control system, a modern integrated system for determining, recording, and remote monitoring of flight parameters. Testing aerial surveys were carried out from a height of $300 \mathrm{~m}$.

After analyzing the quality of the materials obtained, it should be noted that the altitude, flight speed, straightness of the routes, the drift angle, and the longitudinal overlap of the images were satisfactory. The protection of aircraft systems and digital cameras is ensured at the proper level. However, the problem remained unresolved - rather large pitch and roll angles, which is due to insufficient UAV stabilization.

To correct the above shortcomings, a new modification of the "Sky Bow-E" UAV, equipped with a radio beacon and a parachute, was created. The aircraft also has the appropriate navigation equipment, allowing automatic aerial surveys. The study results of the "Sky Bow-G" UAV showed that it meets the basic requirements of traditional aerial surveying:

- maximum flight stability is ensured with the help of appropriate gyro-stabilizing equipment;

- the limitations of the runway were developed: Cabrio with a catapult and landing using a parachute system.

Multiple tests confirmed the correctness of most design solutions, but at the same time, the values of the drift angles remained satisfactory, that is, exceeded the permissible values. The quality of the materials obtained was affected by an incorrect estimate of the wind speed and direction at the flight altitude, which led to an incorrect assessment of the drift angle and, accordingly, the incorrect orientation of the camera relative to the axis of the aircraft.

Similar problems were encountered by the authors (Mahiny \& Turner, 2007; Hadjimitsis et al., 2004; Smith \& Milton, 1999), who concluded that the output image data depends and changes under the influence of factors that include meteorological conditions and camera specifications. Wind and thermal effects can easily cause large angles of external orientation, up to tens of degrees, which is a problem for traditional analytical photogrammetric processing.

Therefore, summarizing the results of the literature analysis, the authors concluded that it was necessary to 
develop a UAV of aircraft type that would meet the standard requirements of aerial surveying, namely:

- ensuring maximum flight stability with appropriate gyro stabilization equipment;

- the presence of a geodetic GPS receiver on board, by which linear elements of the external orientation of the images will be determined with sufficient accuracy $(10-20 \mathrm{~cm})$ in kinematic mode;

- installation of navigation equipment by which manual, semi-automatic and automatic control of the apparatus is realized;

- the presence of an aero device with which angular elements of exterior orientation will be determined with an accuracy of several seconds;

- safety regarding the UAV itself and the onboard equipment (parachute system, beacon);

- the presence of a digital camera with a resolution of not less than 20-60 MP;

- the ability to provide a UAV flight of at least one hour;

- the possibility of transportation of UAV without special means;

- the runway restriction is desirable (implementation of take-off mode and glide path);

- ensuring the determination of the drift angle in flight and its automatic installation using an aero device.

\section{The design of the "Cetus" UAV and its aerial survey equipment}

According to the above requirements, the UAV "Cetus" was developed (Figure 1).

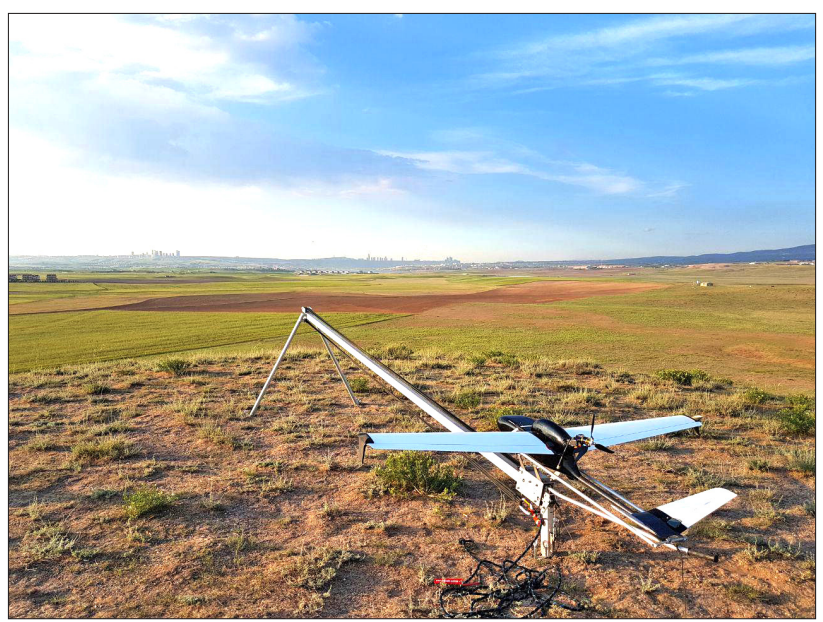

Figure 1. "Cetus" UAV prepared for take-off

The UAV body is made of durable fiberglass and carbon fiber, resistant to external influences, and rubber dampers are used to reduce impact loads during landing. The aircraft automatically compensates for tilt and drift angles using a gyro-stabilized suspension. The aircraft is easily disassembled for transportation in a compact shipping case. The UAV aerial survey and control project is created using a computer with the appropriate software installed. Creation a project of aerial photography and control of UAVs is carried out using Flirt Planner software Abris DG (Abris.Aero, 2020). Due to the installed GNSS L1 / L2 PPK on board, obtaining a high-precision orthophoto map and a digital elevation model is possible without additional fieldwork. Simultaneous use of RGB and multispectral cameras for agricultural monitoring is also possible. Specifications of UAV "Cetus" are presented in Table 1.

Table 1. Specifications of "Cetus" UAV (Hlotov, 2019)

\begin{tabular}{|l|l|}
\hline Total weight & $9 \mathrm{~kg}$ \\
\hline Maximum flight time & 3 hours \\
\hline Flight distance & $180 \mathrm{~km}$ \\
\hline Resistance to weather conditions & $12 \mathrm{~m} / \mathrm{s}$ \\
\hline Resolution & from $1 \mathrm{~cm}$ \\
\hline Glide type & $\begin{array}{l}\text { Parachute, with airbag } \\
\text { payload protection system }\end{array}$ \\
\hline Digital camera & Sony A7RM2 (42 MП) \\
\hline Heat gauge & $\begin{array}{l}\text { FLIR VUE PRO / FLIR } \\
\text { DUO PRO }\end{array}$ \\
\hline GNSS & L1 / L2 PPK GNSS \\
\hline
\end{tabular}

UAV launch is possible both from the arm and from the ejection device. The LuckyLaunch catapult is designed in such a way as to ensure the launch of UAVs weighing from 2 to $10 \mathrm{~kg}$ in various weather conditions and a wide temperature range. The design of high strength aluminum and titanium alloys provides durability, long service life, and minimal weight.

Features:

- modular design and easy adaptation for different types of aircraft and launch conditions;

- high mobility: it can be easily placed in the luggage compartment of the car;

- launch with a running engine;

- excellent dynamic performance over a wide temperature range;

- adjusting the launch angle depending on the wind force;

- fully independent operation - no energy required for its operation;

- simple, safe, and reliable operation and maintenance.

Flight Planner software is used to plan the aerial surveying project, which makes it easy to create missions for fully automated take-off and landing flights. The software calculates wind speed and direction in the area of flight and terrain features in real-time to calculate the best flight and plan aerial mapping with maximum precision.

\section{Advantages:}

- calculation of factors affecting the flight, which cannot be considered manually;

- higher mission performance;

- provision of high-quality aerial mapping material, despite the difficult landscape;

- provision of additional safety for UAVs and on board equipment. 
General Description:

- defining take-off and landing points, aerial survey sites and routes on the map;

- routine flight, route and plane shooting;

- several routes or areas planned in one flight;

- landscape Mission Planning;

- mountain slope terracing;

- support for KML files for importing and exporting mission flight data to Google Earth;

- calculation of image contours on the Earth's surface using terrain elevations shown in the software and exported to KML and Google Earth;

- automated flight program generation for GSD, side, and course overlays for selected cameras and terrain;

- calculation of "drift angles" using real-time weather data and their automatic compensation;

- real-time weather data for optimal flight programming;

- customized aircraft types and payloads that combine easily;

- automatic flight safety check using altitude data;

- calculation of total flight time, distance, power consumption;

- automatically generating and exporting a flight program in terms of MAVLink navigation and autopilot commands to a standard Waypoint file.

In order to coordinate support for the aerial surveying process, a GNSS EPSKit-7 device with a Helix antenna was installed onboard the "Cetus" UAV (Figure 2). The technical characteristics of the device are given in Table 2 .

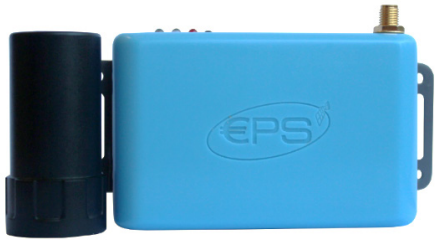

Figure 2. EPSKit-7 with antenna type Helix

This unit is a built-in multifrequency and multi-system GNSS NovAtel OEM7600 card (555 global positioning satellite channels). EPSKit, along with the antenna, is light in weight and extremely small in size for use on board of UAV. It provides continuous recording of current primary measurements using $20 \mathrm{~Hz}$ GNSS (code and phase pseudodistances) signals and the fixation of event markers from one or more digital cameras. The device captures the time of arrival of the marker with an error of up to $20 \mathrm{~ns}$ (standard deviation) and the current (navigational) coordinates of the receiving antenna, corresponding to a given time. The coordinates are fixed in the offline mode of the device and have an error of up to $1.2 \mathrm{~m}$. As a result of the flight, the device forms a single binary file with the following data:

- a set of phase and code measurements of the operating frequencies of signals for each GNSS satellite in the survey, which are recorded 20 times for every second of aircraft flight from the moment of switching on the device;
Table 2. Specifications of the EPSKit-7

\begin{tabular}{|c|c|}
\hline Characteristic & Value \\
\hline $\begin{array}{l}\text { Number of channels } \\
\text { receiving signals }\end{array}$ & 555 \\
\hline Working systems & $\begin{array}{l}\text { GPS, GLONASS, Beidou, Galileo, } \\
\text { SBAS }\end{array}$ \\
\hline Operating frequencies & $\begin{array}{l}\text { L1, L2, L2C, B1, B2, E1, E5 } \\
\text { AltBOC, E5a, E5b }\end{array}$ \\
\hline $\begin{array}{l}\text { Coordinate Accuracy: } \\
\text { - autonomously } \\
\text { - SBAS/EGNOS } \\
\text { - RTK } \\
\text { - after the session }\end{array}$ & $\begin{array}{l}1.2 \mathrm{~m} \\
0.6 \mathrm{~m} \\
1 \mathrm{~cm} \\
1-2 \mathrm{~cm}\end{array}$ \\
\hline $\begin{array}{l}\text { Accuracy of } \\
\text { measurements: } \\
\text { - pseudo-distance (C/A } \\
\text { and P codes) } \\
\text { - carrier phase (L1 and } \\
\text { L2) }\end{array}$ & $\begin{array}{l}0.8 \mathrm{~cm} \\
0.2 \mathrm{~mm}\end{array}$ \\
\hline $\begin{array}{l}\text { Rate of measurement } \\
\text { recording }\end{array}$ & $20 \mathrm{~Hz}$ \\
\hline $\begin{array}{l}\text { The presence of event } \\
\text { markers input }\end{array}$ & So, up to 4 simultaneously \\
\hline Built-in memory card & $8 \mathrm{~Gb}$ \\
\hline Antenna input & SMA female \\
\hline Feeding & 9 to $24 \mathrm{VDC}$ \\
\hline Weight & 120 grams \\
\hline Dimensions & $110 \times 56 \times 27 \mathrm{~mm}$ \\
\hline
\end{tabular}

- set of service digital data on the almanacs and ephemerides of the GNSS satellites of each system;

- the value of the timing of event markers occurrence from a digital camera with an error of up to $20 \mathrm{~ns}$;

- values of current (navigational) coordinates of the aircraft, corresponding to the time of arrival of event markers;

- current timeline status values for all GNSS satellite systems.

\section{The study of aerial survey UAV}

For integrated testing of the "Cetus" UAV, an aerial survey of the Skhodnitsa urban-type village in the mountainous part of the Lviv region was carried out. The height difference in the area is $120 \mathrm{~m}$. The shooting height is $520 \mathrm{~m}$. The shooting area is $13.1 \mathrm{~km}^{2}$. As a result of the aerial survey, 460 images were obtained from 11 survey routes. Differences in aerial photographs in the area (GSD) are 7 $\mathrm{cm} /$ pixel.

To determine the operational efficiency of the aircraft, a comparative analysis of the drift angle, roll and pitch of the "Cetus" UAV along each route was made. For example, in Figures 3-5 graphs along one route are presented.

Analyzing the graphs constructed on the roll, pitch, and drift angles (Figures 3-5), it should be noted that, on average, they do not exceed the tolerances for scheduled 


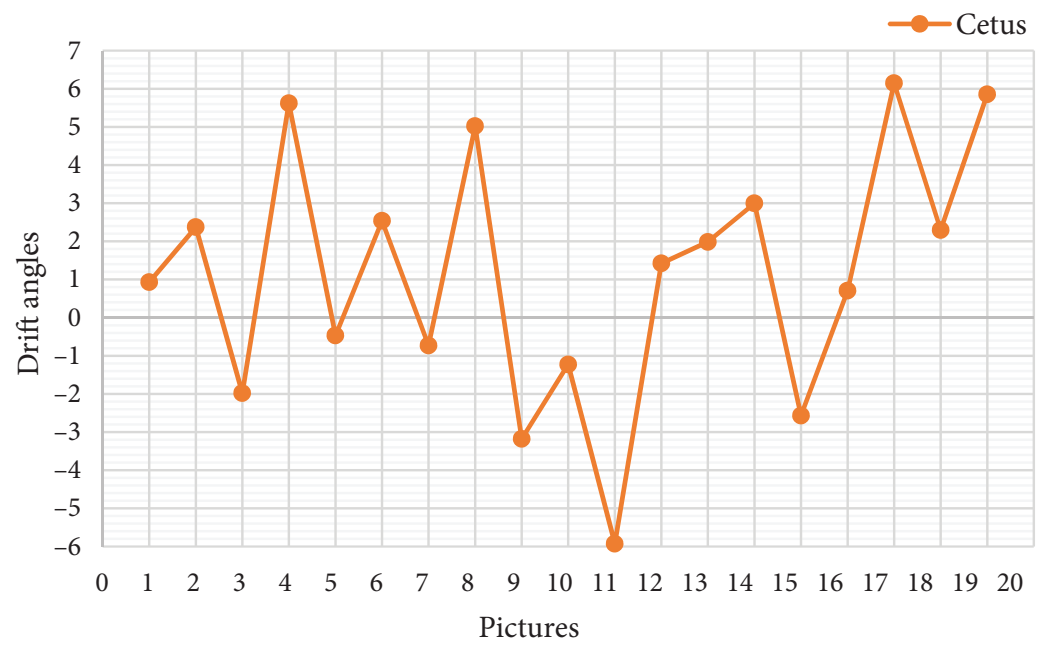

Figure 3. The drift angle values of the "Cetus" UAV

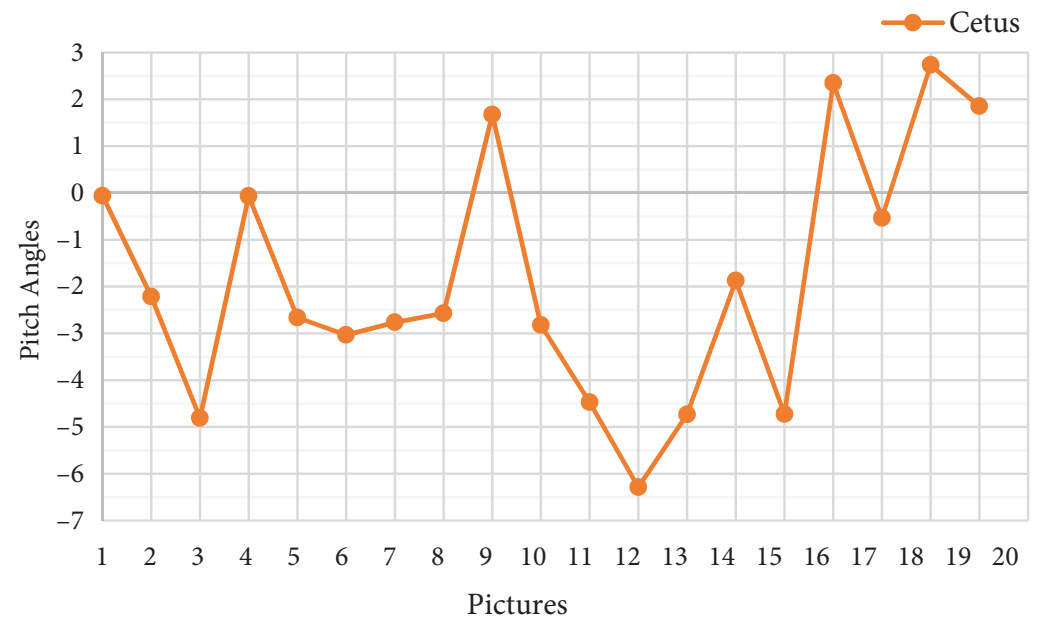

Figure 4. Values of "Cetus" UAV pitch angles

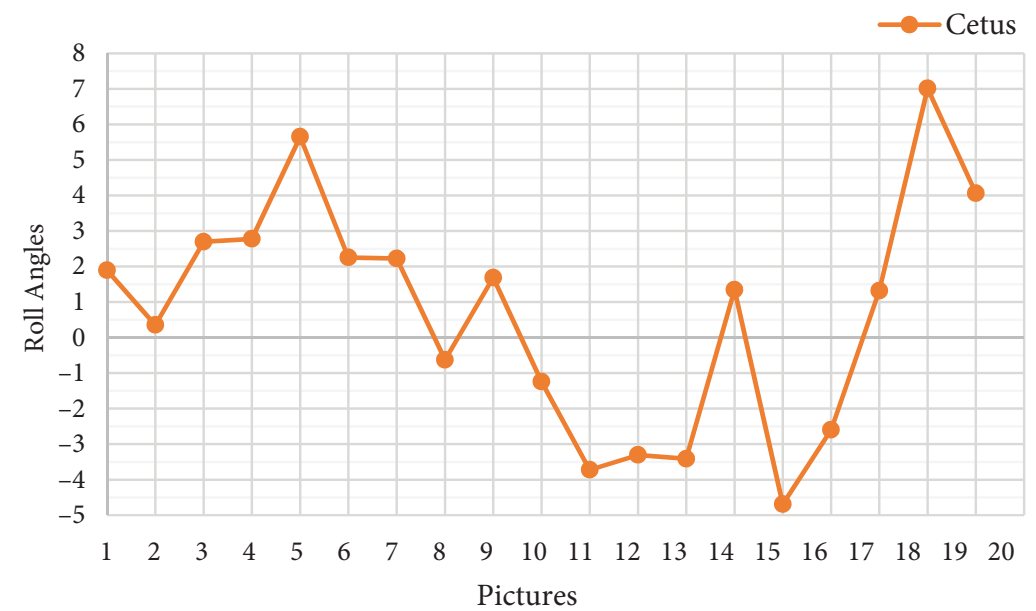

Figure 5. Values of "Cetus" UAV roll angles 
aerial surveying. Thus, the accuracy of determining the spatial coordinates of points of terrain objects will improve significantly, as confirmed by the processing of aerial surveying, which is presented in the next section.

\section{Evaluation of aero triangulation accuracy}

We created an aero triangulation network to study the possibility of photogrammetric processing. The terrestrial network of reference and control points was created by GPS survey. The points were chosen on natural and artificial contours of the terrain without artificial marking. The main requirements when choosing the placement of points were their good recognizability in aerial photographs, the absence of high objects nearby, such as trees and buildings. The number, spatial distribution and accuracy of determining the coordinates of reference and control points correspond to the recommendations (American Society for Photogrammetry and Remote Sensing, 2014). In total, 14 reference points (12 horizontal and 2 vertical points) and 23 control points located uniformly in the shooting area were used in photogrammetric processing. The spatial coordinates of the points were determined with accuracy:

$$
\text { RMSEx }=\text { RMSEy }=0.02 \mathrm{~m} \text { and } \mathrm{RMSEz}=0.03 \mathrm{~m} \text {. }
$$

These accuracy indicators correspond to the requirements for this type of data when creating topographic plans and orthophoto maps of 1: 1000 and 1: 2000 scales. For these scales, we take:

$$
\begin{aligned}
& \operatorname{RMSE}_{\mathrm{X}(\mathrm{MAP})}=\mathrm{RMSE}_{\mathrm{Y}(\mathrm{MAP})}=0.2 \mathrm{~m} \\
& \text { and } \mathrm{RMSE}_{\mathrm{Z}(\mathrm{MAP})}=0.33 \mathrm{~m} .
\end{aligned}
$$

We consider the known ratios of the standard errors of determining the coordinates of the plan points and the standard errors of determining the coordinates of the reference networks points (American Society for Photogrammetry and Remote Sensing, 2014):

$\mathrm{RMSE}_{\mathrm{X}}$ or $\mathrm{RMSE}_{\mathrm{Y}}=1 / 4 \mathrm{RMSE}_{\mathrm{X}(\mathrm{MAP})}$ or $\mathrm{RMSE}_{\mathrm{Y}(\mathrm{MAP})}$;

$$
\mathrm{RMSEz}=1 / 2 \mathrm{RMSE}_{\mathrm{X}(\mathrm{MAP})} \text { or } \mathrm{RMSE}_{\mathrm{Y}(\mathrm{MAP})} .
$$

To create a network of phototriangulation and orthophoto map, we used Pix4D software. The results of assessing the accuracy of the photogrammetric network for reference ( 14 points) and control points (23 points) are shown in Table 3.

The given parameters indicate the possibility of using aerial survey data to create topographic plans and orthophoto maps with a scale of 1: 1000 and 1: 2000 .

Table 3. Ferotriangulation network accuracy assessment results

\begin{tabular}{|l|c|c|c|}
\hline & $\mathrm{RMSE}_{\mathrm{X}}(\mathrm{m})$ & $\mathrm{RMSE}_{\mathrm{Y}}(\mathrm{m})$ & $\mathrm{RMSE}_{\mathrm{Z}}(\mathrm{m})$ \\
\hline By reference points & 0.056 & 0.048 & 0.042 \\
\hline By control points & 0.121 & 0.081 & 0.315 \\
\hline
\end{tabular}

\section{Conclusions}

The requirements for the design of aerial survey systems are identified.

1. The angular elements values analysis for the external orientation of the images obtained as a result of aerial surveys with UAV "Cetus" is conducted.

2. It is proved that the use of "Cetus" UAV allows creating orthophoto maps on a scale of 1: $1000-$ 1: 2000 with the corresponding accuracy of determining the planned coordinates.

3. In the future, it is planned to study the processing of orthophoto maps, topographic plans and the creation of 3D models of terrain objects based on materials obtained from "Cetus" UAVs at various shooting scales, the configuration of the location of the reference network and the navigation parameters of the onboard two-frequency GPS receiver.

\section{References}

Abris.Aero. (2020). https://abris.aero/abris-flightplanner-software

American Society for Photogrammetry and Remote Sensing. (2014). ASPRS positional accuracy standards for digital geospatial data (ed. 1, version 1.0). Photogrammetric Engineering \& Remote Sensing, 81(3), A1-A26. https://www.asprs.org/wpcontent/uploads/2015/01/ASPRS_Positional_Accuracy_Standards_Edition1_Version100_November2014.pdf

Bryson, M., Reid, A., Ramos, F., \& Sukkarieh, S. (2010). Airborne vision-based mapping and classification of large farmland environments. Journal of Field Robotics, 27(5), 632-655. https://doi.org/10.1002/rob.20343

Fernández-Hernandez, J., González-Aguilera, D., RodríguezGonzálvez, P., \& Mancera-Taboada, J. (2015). Image-based modeling from unmanned aerial vehicle (UAV) photogrammetry: An effective, low-cost tool for archaeological applications. Archaeometry, 57(1), 128-145.

https://doi.org/10.1111/arcm.12078

Hadjimitsis, D., Clayton, C., \& Hope, V. (2004). An assessment of the effectiveness of atmospheric correction algorithms through the remote sensing of some reservoirs. International Journal of Remote Sensing, 25(18), 3651-3674. https://doi.org/10.1080/01431160310001647993

Haletskyi, V., Hlotov, V., Kolesnichenko, V., Prokhorchuk, O., \& Tserklevych, A. (2012a). Analiz eksperymentalnykh robit $z$ stvorennia velykomasshtabnykh planiv silskykh naselenykh punktiv pry zastosuvanni BPLA [Analysis of experimental works on creation of large-scale plans of rural settlements in the application of UAV]. Heodeziia, kartohrafiia i aerofotoznimannia, 76, 85-93.

Haletskyi, V., Hlotov, V., Kolesnichenko, V., Prokhorchuk, O., \& Tserklevych, A. (2012b). Druhyi etap eksperymentalnykh robit $\mathrm{z}$ aeroznimannia silskykh naselenykh punktiv BPLA [The second stage of experimental work on aerial survey of rural settlements of UAV]. Heoinformatsiinyi monitorynh navkolyshnoho seredovyshcha GPS $i$ GIS tekhnolohii: $z b$. nauk. mater. XVII Mizhn. nauk.-tekhn. Sympoziumu, 274-277.

Hlotov, V., Tserklevych, A., Zbrutskyi, O., Kolisnichenko, V., Prokhorchuk, O., Karnaushenko, R., \& Haletskyi, V. (2014). Analiz i perspektyvy aeroznimannia z bezpilotnoho litalnoho aparata [Analysis and prospects of aerial photography 
from an unmanned aerial vehicle]. Suchasni dosiahnennia heodezychnoi nauky ta vyrobnytstva, 1(27), 131-136.

Hlotov, V. M., \& Hunina, A. V. (2017). Sposib vyznachennia fokusnoi viddali tsyfrovoi znimalnoi kamery [A method for determining the focal length of a digital camera]. (Ukraine, Patent No. 121758). Ukrainian Patent and Trademark Office.

Hlotov, V. M., \& Hunina, A. V. (2018). Sposib vyznachennia fokusnoi viddali tsyfrovoi znimalnoi kamery [A method for determining the focal length of a digital camera]. (Ukraine, Patent No. 130494). Ukrainian Patent and Trademark Office.

Hlotov, V., Hunina, A., Kolesnichenko, V., Prokhorchuk, O., \& Yurkiv, M. (2018). Development and investigation of UAV for aerial surveying. Geodesy, Cartography and Aerial Photography, 87, 48-57. https://doi.org/10.23939/istcgcap2018.01.048

Kostyuk, A. (2011). Osobennosti aerofotos'emki so sverhlegkih bespilotnyih letatelnyih apparatov [Features of aerial photography from ultralight unmanned aerial vehicles]. Omskiy nauchnyiy vestnik, 1(104), 236-240.

Levytskyi, V. (2008). Udoskonalennia metodyky analitychnoi obrobky znimkiv, otrymanykh nemetrychnymy tsyfrovymy kameramy pry vykonanni fotohrammetrychnoi ziomky [Improvement of the method of analytical processing of images obtained by nonmetric digital cameras when performing photogrammetric shooting]. Visnyk Zhytomyrskoho derzhavnoho tekhnolohichnoho universytetu. Tekhnichni nauky, 1(44), 154-164.
Mahiny, A. S., \& Turner, B. J. (2007). A comparison of four common atmospheric correction methods. Photogrammetric Engineering \& Remote Sensing, 73(4), 361-368. https://doi.org/10.14358/PERS.73.4.361

Rokhmana, C. A. (2015). The potential of UAV-based remote sensing for supporting precision agriculture in Indonesia. Procedia Environmental Sciences, 24, 245-253. https://doi.org/10.1016/j.proenv.2015.03.032

Shevenia, M. (2013). Aerofotos'emka s prymenenyem bespylotnyikh letatelnyikh apparatov (BPLA) [Aerial photography using unmanned aerial vehicles (UAVs)]. Geodesy and Cartography, 1. http://baltagp.ru/aerophoto/

Smith, G. M., \& Milton, E. J. (1999). The use of the empirical line method to calibrate remotely sensed data to reflectance. International Journal of Remote Sensing, 20(13), 2653-2662. https://doi.org/10.1080/014311699211994

Tsytsokhov, D., \& Boiko, O. (2014). Vykonannia topohrafoheodezychnykh robit $\mathrm{z}$ vykorystanniam bezpilotnykh litalnykh aparativ [Execution of topographic-geodetic works with the use of unmanned aerial vehicles]. In Second AllUkrainian Scientific and Technical Conference of Students, Graduate Students and Young Scientists, "Youth: Science and Innovation" (Vol. 5, Section 6 - Surveying and land management). http://science.nmu.org.ua/ua/conferences/ molod-nauka-ta-innov/pdf-2014/20150204-06.pdf 